\title{
Fatigue Life Analysis of Rolling Bearings Based on Quasistatic Modeling
}

\author{
Wei Guo, Hongrui Cao, Zhengjia He, and Laihao Yang \\ State Key Laboratory for Manufacturing Systems Engineering, Xian Jiaotong University, Xi'an 710049, China \\ Correspondence should be addressed to Hongrui Cao; chr@mail.xjtu.edu.cn
}

Received 27 February 2015; Accepted 28 April 2015

Academic Editor: Changjun Zheng

Copyright ( 2015 Wei Guo et al. This is an open access article distributed under the Creative Commons Attribution License, which permits unrestricted use, distribution, and reproduction in any medium, provided the original work is properly cited.

\begin{abstract}
Rolling bearings are widely used in aeroengine, machine tool spindles, locomotive wheelset, and so forth. Rolling bearings are usually the weakest components that influence the remaining life of the whole machine. In this paper, a fatigue life prediction method is proposed based on quasistatic modeling of rolling bearings. With consideration of radial centrifugal expansion and thermal deformations on the geometric displacement in the bearings, the Jones' bearing model is updated, which can predict the contact angle, deformation, and load between rolling elements and bearing raceways more accurately. Based on Hertz contact theory and contact mechanics, the contact stress field between rolling elements and raceways is calculated. A coupling model of fatigue life and damage for rolling bearings is given and verified through accelerated life test. Afterwards, the variation of bearing life is investigated under different working conditions, that is, axial load, radial load, and rotational speed. The results suggested that the working condition had a great influence on fatigue life of bearing parts and the order in which the damage appears on bearing parts.
\end{abstract}

\section{Introduction}

Rolling bearings are widely used in rotating machinery system such as aeroengine rotors system, machine tool spindles, and train wheelset. However, they are the weak links of mechanical because their mechanical properties and operating state have significant impact on precision, reliability, and life of the whole system. The failure of rolling bearings not only affects the performance of mechanical equipment, but also causes serious accident. Thus, fatigue life prediction for rolling bearing has important theoretical significance and practical value.

The dynamics behavior of rolling bearings is observably affected by factors such as centrifugal force, gyroscopic moment, friction, thermal deformation, and external load on unconventional conditions like high speed and high accelerated velocity. In this case, the movement inside rolling bearing becomes very complex. Besides pure rolling contact between rolling elements and raceways, motions like spinning and skidding are accompanied. The failure mechanism analysis, fault diagnosis, and life prediction for rolling bearings become more difficult because of the significant change of contact angle and contact load distribution. Incipient failure diagnosis is of great significance for key major equipment. However, the response signals reflect incipient failures of rolling bearings are not obvious and easy to be disturbed by pathways and working noises, which bring new challenges to fault diagnosis technology based on signal processing and feature extraction. On fault diagnosis of rolling bearing, researchers developed fault detect and diagnostic techniques based on vibration and signal processing [1-4]. Patil et al. [5] reviewed the research status of fault diagnosis on rolling bearings. Research on fault modeling theory and failure mechanism for rolling bearings is particularly inadequate compared with fault detecting techniques. In recent years, studies on rolling bearings fault modeling gain more and more attention from researchers. Cao and Xiao [6] established complicated dynamical model for self-aligning roller bearing. Surface damage, pretension, and radial clearance problems were studied. Sawalhi and Randall [7] integrated nonlinear bearing model with model of gear and simulated spalling damage of bearings. Rafsanjani et al. [8] developed a nonlinear dynamical model for rolling bearings, and provided 
mathematical description for roller, inner raceway, and outer raceway. Patel et al. [9] established a dynamical model for deep groove ball bearing to study the vibration response when single point or multipoint faults existing on inner and outer raceways. Above researches for dynamic simulation of rolling bearings are helpful to understand the failure mechanism and characteristic of bearings and provide fundamental basis for monitoring and fault diagnosis of rolling bearings to some extent. However, most of the models do not consider the influence of parameters such as rotational speed, operation temperature rise, and external load. Considering the centrifugal expansion and thermal deformation when inner raceway rotating, Cao et al. [10, 11] improved Jones' rolling bearing model [12]. A mechanical model for high speed rolling bearing was developed and verified by experiments. Contact loads and contact positions inside rolling bearings under static load, dynamic load, and high rotational speed were studied.

The rolling bearing failure is typical rolling contact fatigue [13]. Because fatigue spall of material originating from subsurface caused by rolling contact is the main failure form of rolling bearing [14], researchers put forward a lot of rolling contact fatigue models to predict rolling bearing life in past decades. The deterministic research models for rolling contact fatigue (RCF), as an important class of bearing life models, consider complete stress-strain behavior information of materials under contact loading [15]. Taraf et al. [16] studied the modeling of the rolling contact fatigue initiation life, which was simulated with moving Hertzian contact pressure. It was found that the size and shape of defects in material played an important role in fatigue crack initiation. Deshpande and Chandra Kishen [17] proposed a method for rolling contact fatigue crack propagation analysis with the concepts of Hertzian contact mechanics associated with fracture mechanics. This algorithm could be used to determine whether the bearing failure caused by crack propagation. Using the method of equivalent initial flaw size, Liu and Mahadevan [18] applied the propagation model to calculate initiation fatigue life. Then, the model for crack initiation and growth was obtained. Liu and Choi [19] developed a method to model the RCF life of finish hard machined surfaces and proved by experiment. The RCF model was based on both the crack initiation life and the crack propagation life.

Calculation of contact stress field is essential for the prediction of bearing fatigue life, and many studies have been conducted on solving contact stress field and RCF problems. Hertz created elasticity contact theory, providing foundation of contact stress analysis and calculation. Hertz theory provided formula of surface stress field in corresponding contact area. Lundberg and Palmgren [20] simplified Hertz contact problem. Corresponding contact parameters could be obtained just by querying contact coefficient tables. Lots of tests proved rolling contact fatigue often initiated in subsurface, therefore, the analysis for subsurface stress field of contact area is important to research failure mechanism and life prediction of contact fatigue [13]. Johnson [21] gave a formula to calculate the principal stress at any depth in the subsurface of contact area. Sadeghi's group [22-25] developed a Voronoi finite element model to simulate the microstructure of material and calculate the stress field of contact area. The effect of microstructure of material on contact stress field and rolling contact fatigue life was discussed.

Traditional researches were mostly based on models for contact between single roller and raceway, but these models have not developed whole mechanical model to analyze stress of a whole bearing. Meanwhile, the influences of parameters like bearing structure and operating condition on bearing life were not considered. Based on modified Jones' model [12], this paper analyzes mechanics principle of a bearing and solves contact loads and contact angles under high-speed conditions. On the basis of the above model, stress field of surface and subsurface of bearing is calculated by dichotomy. Then, a coupling model of life and damage which considering the mechanical property of a bearing is established to predict the fatigue initiation life of bearing parts, and qualitatively verified through accelerated life test.

\section{Quasistatic Modeling for Rolling Bearings}

The movement inside an angular contact ball bearing becomes complicated at high speed. The contact load and the contact angle are significantly changed because of centrifugal forces and gyroscopic moments. Moreover, operating temperature will increase with the run time growing so that thermal deformation occurs on bearings. These cause significant change on contact stress field and then affect the fatigue life of rolling bearing. Jones' bearing model is a more complete bearing mechanics mode; however, it has not considered the dilatational strain caused by rapid rising temperature and centrifugal force. In this paper, the Jones' bearing model is improved with the consideration of effect of centrifugal force and gyroscopic couple and can take the influences of radial thermal expansion and centrifugation expansion of inner raceway on geometric displacement inside the bearing into account. So the contact load and the contact angle under the influences of these factors can be calculated.

\subsection{Geometrical Properties of an Angular Contact Ball Bearing.}

The typical geometric construction of an angular contact ball bearing is shown in Figure 1. In the figure, $\varphi_{k}$ is the azimuth angle of the $k$ th roller. Based on finite element idea, a rolling bearing can be viewed as an element comprised of an inner raceway node and an outer raceway node. The motion of each node contains 5 degrees of freedom (DOFs). In order to facilitate the analysis, the outer raceway is fixed. Set the relative displacements of these 5 DOFs between inner raceway and outer as $\Delta \delta_{x}, \Delta \delta_{y}, \Delta \delta_{z}, \Delta \gamma_{y}$, and $\Delta \gamma_{z}$.

As shown in Figure 2, when rolling bearings operated, the relative positions of inner raceway, rolling element and outer raceway will be changed. The inner raceway and rolling element have moved to new locations, respectively, after bearings reach equilibrium states. Then, the distances between curvature centre of raceways and roller are as follows:

$$
\begin{gathered}
\Delta_{i k}=r_{i}-0.5 D+\delta_{i k}=\left(f_{i}-0.5\right) D+\delta_{i k}, \\
\Delta_{o k}=r_{o}-0.5 D+\delta_{o k}=\left(f_{o}-0.5\right) D+\delta_{o k},
\end{gathered}
$$




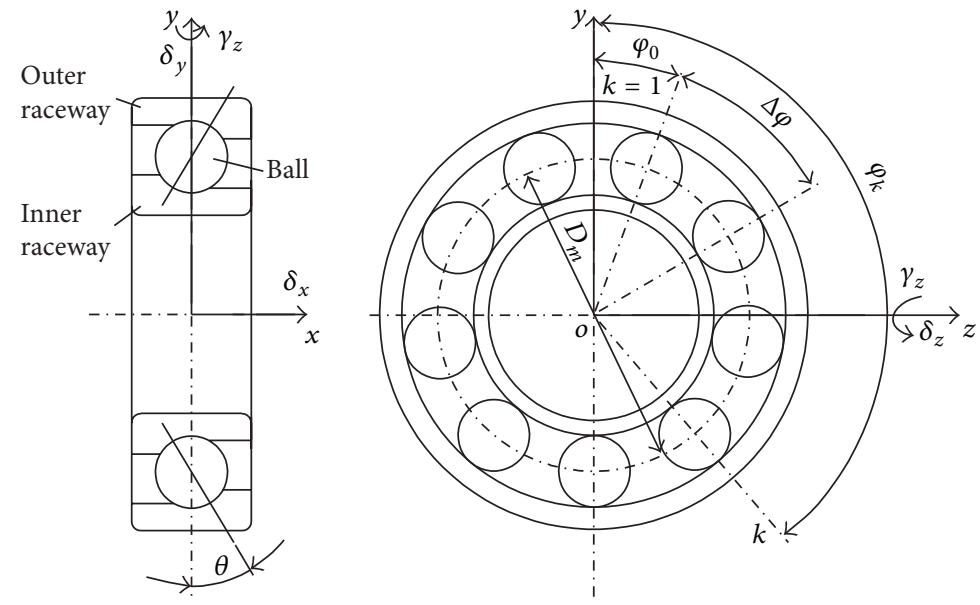

FIGURE 1: Geometric drawing of rolling bearings.

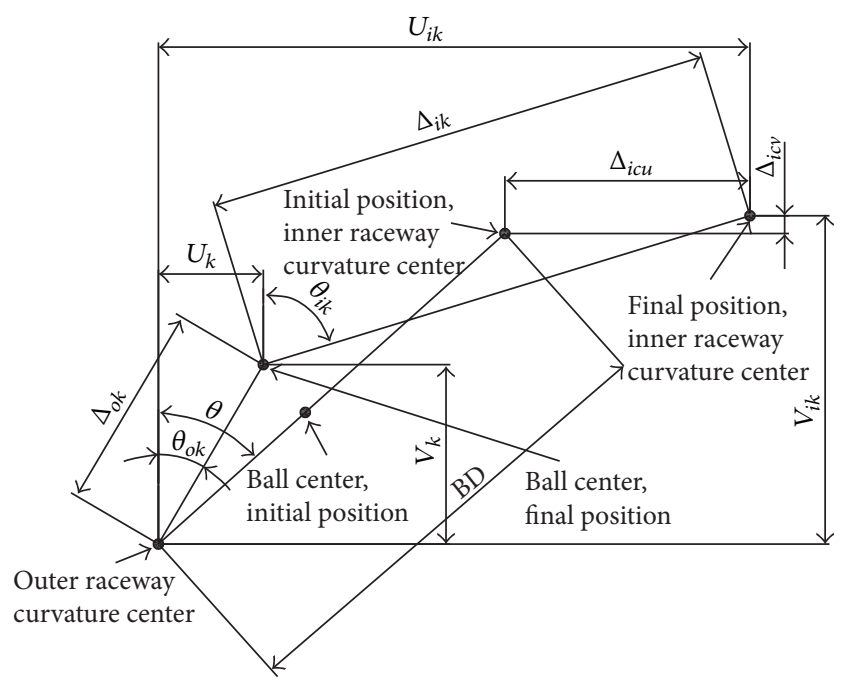

FIGURE 2: Geometric relationship of bearing inner raceway, outer raceway, and rolling elements.

where subscript $i$ and $o$ indicate inner raceway and outer raceway, respectively, $r$ is curvature radius, $D$ is the diameter of rollers, $f$ is ratio of diameter of roller to curvature radius of raceways, and $\delta_{i k}$ and $\delta_{o k}$ are contact deformation displacements of rollers on inner raceway and outer raceway, respectively.

The relative displacement variation of inner raceway curvature center is as follows:

$$
\begin{aligned}
\Delta_{i c u} & =\Delta \delta_{x}-\Delta \gamma_{z} r_{i c} \cos \varphi_{k}+\Delta \gamma_{y} r_{i c} \sin \varphi_{k}, \\
\Delta_{i c v} & =\Delta \delta_{y} \cos \varphi_{k}+\Delta \delta_{z} \cos \varphi_{k}+\varepsilon_{i r}+u_{i r}-\varepsilon_{o r},
\end{aligned}
$$

where $\varepsilon_{i r}$ and $\varepsilon_{o r}$ are radial thermal expansion of inner raceway and outer raceway, respectively, which can be obtained by finite element heat analysis [26], $u_{i r}$ is the expansion of inner raceway under the action of centrifugal force.
Using the Pythagorean Theorem, it can be seen from Figure 2 that the displacement of bearing internal structure in working state is

$$
\begin{aligned}
\left(U_{i k}-U_{k}\right)^{2}+\left(V_{i k}-V_{k}\right)^{2}-\Delta_{i k}^{2} & =0, \\
U_{k}^{2}+V_{k}^{2}-\Delta_{o k}^{2} & =0 .
\end{aligned}
$$

Accordingly, the trigonometry function of contact angle between bearing raceways and rolling elements can be described as follows:

$$
\begin{aligned}
& \sin \theta_{i k}=\frac{U_{i k}-U_{k}}{\Delta_{i k}}, \\
& \cos \theta_{i k}=\frac{V_{i k}-V_{k}}{\Delta_{i k}}, \\
& \sin \theta_{o k}=\frac{U_{k}}{\Delta_{o k}}, \\
& \cos \theta_{o k}=\frac{V_{k}}{\Delta_{o k}} .
\end{aligned}
$$

2.2. Force Balance Analysis. When angular contact ball bearings operate at high speeds, the contact between rolling element and raceways is not pure rolling contact but along with motions such as spinning and skidding. To simplify matters in practice, assume that pure rolling only occurs between ball and inner raceway or outer raceway, and both spinning and skidding exist on the other raceway. Considering centrifugal force and gyroscopic couple on balls, the force of the $k$ th ball is analyzed on the plane constructed by bearing axis and ball center, as shown in Figure 3. 


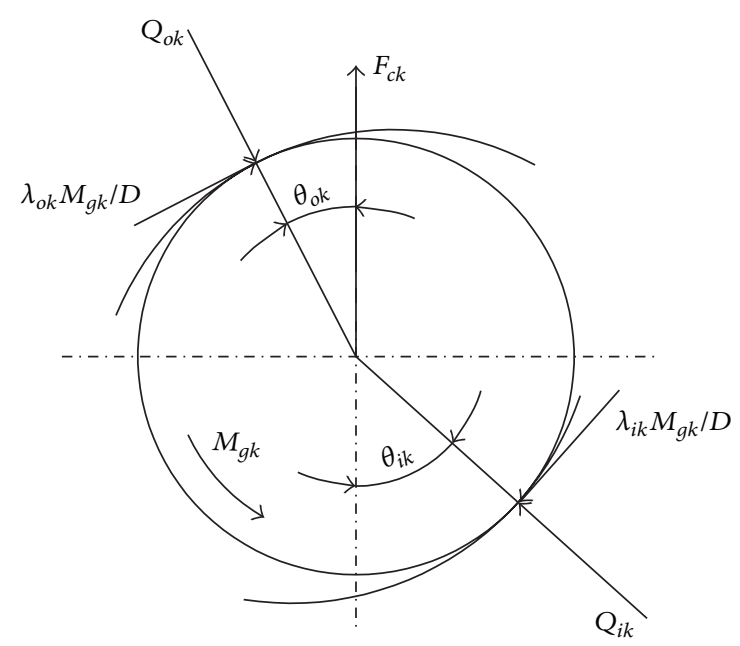

$\theta_{i k}$ : ball, inner raceway contact angle $\left({ }^{\circ}\right)$;

$Q_{o k}$ : ball, inner raceway contact load $(\mathrm{N})$;

$F_{c k}$ : centrifugal force for balls $(\mathrm{N})$;

$\theta_{o k}$ : ball, outer raceway contact angle $\left({ }^{\circ}\right)$;

$\mathrm{Q}_{o k}$ : ball, outer raceway contact load (N);

$M_{g k}$ : gyroscopic moment for balls $(\mathrm{N} \cdot \mathrm{m})$

FIGURE 3: Force analysis of rolling balls.

From Figure 3, considering the equilibrium of forces in the horizontal and vertical directions:

$$
\begin{aligned}
& Q_{o k} \cos \theta_{o k}-Q_{i k} \cos \theta_{i k}-\frac{M_{g k}}{D}\left(\sin \theta_{o k}-\sin \theta_{i k}\right) \\
& \quad-F_{c k}=0, \\
& Q_{o k} \sin \theta_{o k}-Q_{i k} \sin \theta_{i k}+\frac{M_{g k}}{D}\left(\cos \theta_{o k}-\cos \theta_{i k}\right)=0,
\end{aligned}
$$

where $\theta_{i k}$ and $\theta_{o k}$ are contact angle of inner raceway and outer raceway, $F_{c k}$ and $M_{g k}$ are centrifugal force and gyroscopic moment for rollers, respectively; $Q_{i k}$ and $Q_{o k}$ are ball-inner and ball-outer raceway contact load respectively, $\lambda_{i k}$ and $\lambda_{o k}$ are corrected parameters of raceway control mode, for the outer raceway controlling case $\lambda_{i k}=0$ and $\lambda_{o k}=2$, while $\lambda_{i k}=\lambda_{o k}=1$ in any other cases. This will not cause much influence to computational accuracy [27]:

$$
\begin{gathered}
Q_{i k}=K_{i} \delta_{i k}^{3 / 2}, \\
Q_{o k}=K_{o} \delta_{o k}^{3 / 2},
\end{gathered}
$$

where $K_{i}$ and $K_{o}$ are, respectively, load deflection constants of ball-inner and ball-outer raceway contact $[27,28]$. Under a joint result of static load and thermal deformation, the ball-inner raceway contact deformation $\delta_{i k}$ and ball-outer raceway contact deformation $\delta_{o k}$ are

$$
\begin{gathered}
\delta_{i k}=\Delta_{i k}+\varepsilon_{b}-\left(f_{i}-0.5\right) D, \\
\delta_{o k}=\Delta_{o k}+\varepsilon_{b}-\left(f_{o}-0.5\right) D,
\end{gathered}
$$

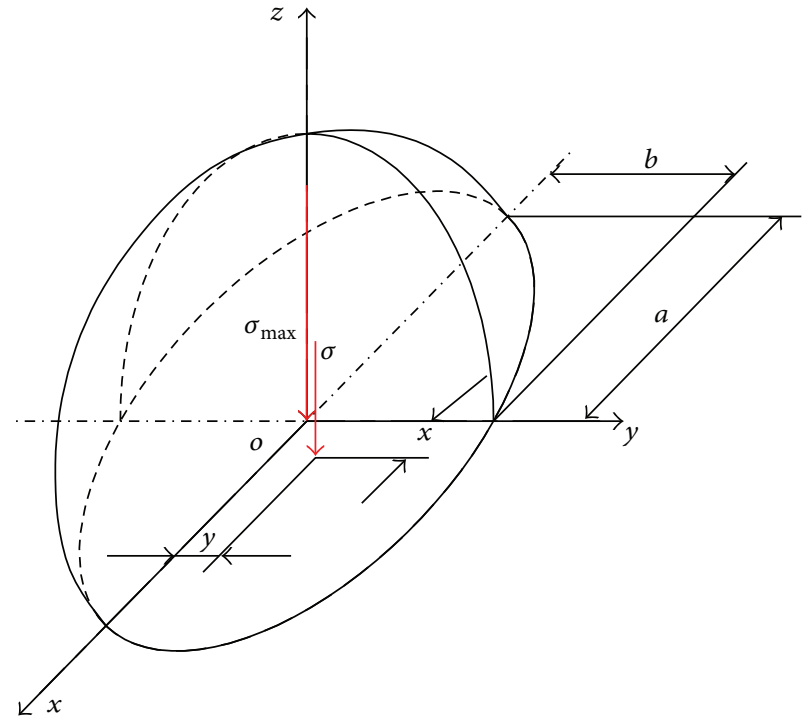

FIGURE 4: Ellipsoidal surface compressive stress distribution of point contact.

where $\varepsilon_{b}$ is thermal expansion deformation, which can be obtained by finite element heat analysis.

From (3) and (5), the unknown parameters $U_{k}, V_{k}, \delta_{o k}$, and $\delta_{i k}$ will be solved with Newton iteration method; thus, the contact angle and the contact load are obtained.

\section{Life Prediction Model of Rolling Contact Bearing}

3.1. Contact Stress Field Modeling and Numerical Solution inside Angular Contact Ball Bearing. The contact stress field between rolling element and raceway is altered because of the significant changing of contact angle and contact load under high speed rotation, which will affect the fatigue life of rolling bearings. Therefore, it is very important to established contact stress model of relationship between rolling element and raceway and to find the high efficiency numerical solution method.

3.1.1. Ball-Raceway Contact Mechanics Model. In angular contact ball bearings, the contact zone between a ball and a raceway is elliptical based on Hertz contact theory. Surface stress distribution inside the contact area has a semiellipsoid as shown in Figure 4. In the figure, $a$ and $b$ are the semimajor and semiminor axes of the elliptical area of contact, respectively.

When the contact load is $Q$, the normal stress at any point $(x, y)$ in the contact area surface can be expressed as follows [13]:

$$
\sigma=\sigma_{\max }\left[1-\left(\frac{x}{a}\right)^{2}-\left(\frac{y}{b}\right)^{2}\right]^{1 / 2},
$$

where $\sigma_{\max }$ is the maximum contact stress at contact ellipse center. From Hertz contact theory, the semimajor axis $a$, 
semiminor axis $b$, and elastic contact deformation $\delta$ are shown as follows [13]:

$$
\begin{aligned}
& a=a^{*}\left[\frac{3 Q}{2 \sum \rho}\left(\frac{1-\xi_{1}^{2}}{E_{1}}+\frac{1-\xi_{2}{ }^{2}}{E_{2}}\right)\right]^{1 / 3}, \\
& b=b^{*}\left[\frac{3 Q}{2 \sum \rho}\left(\frac{1-\xi_{1}{ }^{2}}{E_{1}}+\frac{1-\xi_{2}{ }^{2}}{E_{2}}\right)\right]^{1 / 3}, \\
& \delta=\delta^{*}\left[\frac{3 Q}{2 \sum \rho}\left(\frac{1-\xi_{1}{ }^{2}}{E_{1}}+\frac{1-\xi_{2}{ }^{2}}{E_{2}}\right)\right]^{2 / 3} \frac{\sum \rho}{2},
\end{aligned}
$$

where $E_{i}(i=1,2)$ is Young's modulus (MPa), $\xi_{i}(i=1,2)$ is Poisson's ratio, and $\kappa$ is a supplementary parameter, $\kappa=a / b$. Thus, parameters $a^{*}, b^{*}$, and $\delta^{*}$ can be represented as

$$
\begin{aligned}
& a^{*}=\left(\frac{2 \kappa^{2} E}{\pi}\right)^{1 / 3}, \\
& b^{*}=\left(\frac{2 E}{\pi \kappa}\right)^{1 / 3}, \\
& \delta^{*}=\frac{2 K}{\pi}\left(\frac{\pi}{2 \kappa^{2} E}\right)^{1 / 3},
\end{aligned}
$$

where $K$ and $E$ are the complete elliptic integrals of the first and second kind, respectively [29].

According to (10), the key to the solution of Hertz contact problem is to obtain the value of supplementary parameter $\kappa$.

3.1.2. Numerical Solution of Contact Model. Harris and Kotzalas [13] and Lundberg and Palmgren [20] suggested simplified computational methods to calculate Hertz contact stress. However, these methods all make approximation to model parameters, which result in certain errors. It will not only affect the calculation accuracy of contact area stress field, but also cause some error to the calculation of rolling contact fatigue life. Therefore, dichotomy is used to simulate the Hertz point contact problem, to reduce the error of contact stress analysis. Figure 5 shows the program chart.

In order to determine the contact ellipse parameter $\kappa$, firstly the eccentricity of contact ellipse $e$ should be confirmed, while $e$ can be obtained from the following equation [27]:

$$
\frac{\left(2-e^{2}\right) E(m)-2\left(1-e^{2}\right) K(m)}{e^{2} E(m)}=F(\rho),
$$

where $m$ is a supplementary parameter, with the value of $m=$ $e^{2}$ :

$$
e=\sqrt{1-\kappa^{2}} .
$$

$K(m)$ and $E(m)$ are the complete elliptic integrals of the first and the second kinds, respectively. $F(\rho)$ is a function of principal curvature of contact bodies:

$$
F(\rho)=\frac{\left|\rho_{1 \mathrm{I}}-\rho_{1 \mathrm{III}}\right|+\left|\rho_{2 \mathrm{I}}-\rho_{2 \mathrm{II}}\right|}{\sum \rho},
$$

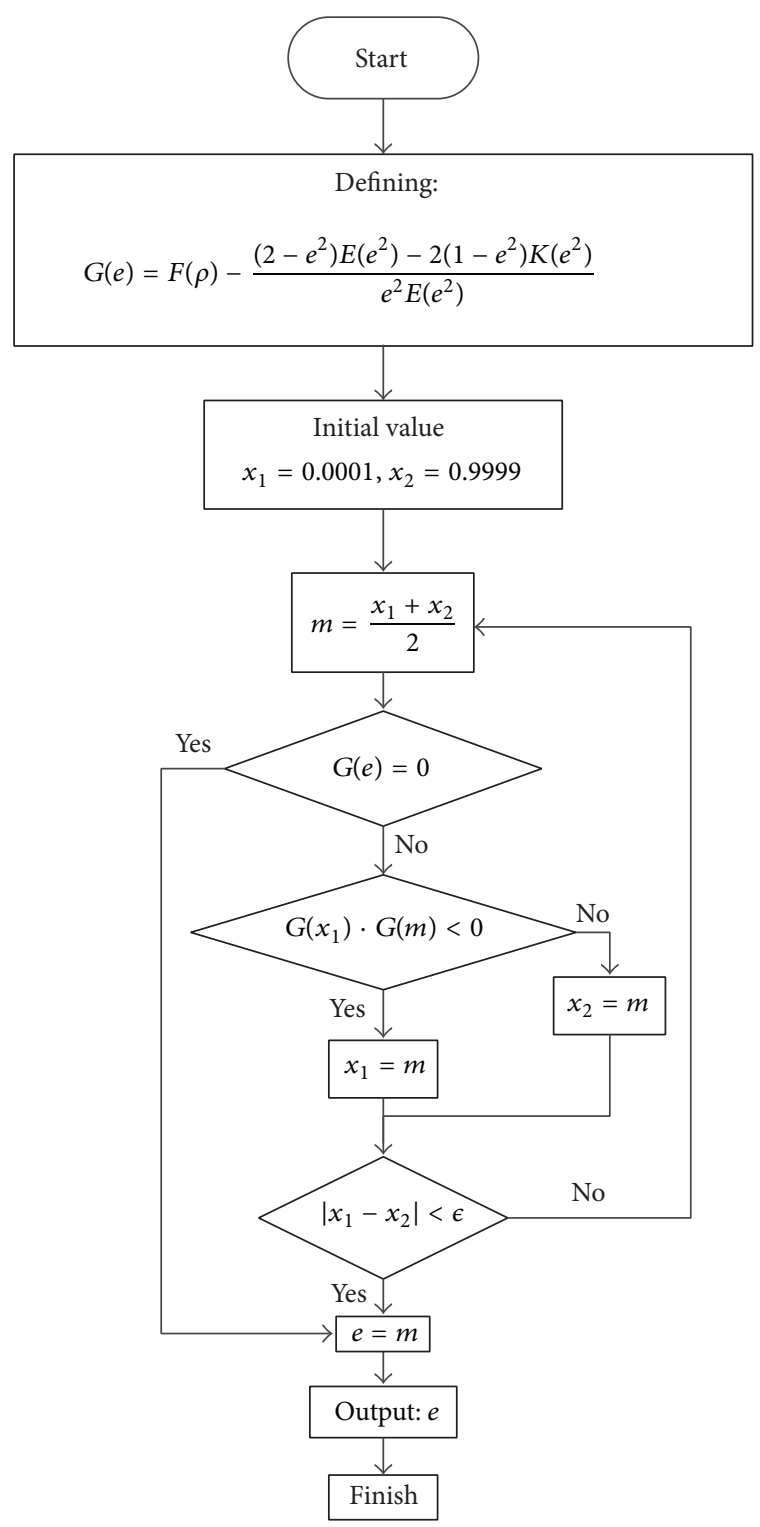

FIgUre 5: Program chart of dichotomy.

where $\rho_{i j}(i=1,2 ; j=\mathrm{I}, \mathrm{II})$ is the principal curvature of contact body, $\sum \rho$ is the sum of principal curvature [13].

Function $G(e)$ is defined for the convenience of solving

$$
G(e)=F(\rho)-\frac{\left(2-e^{2}\right) E\left(e^{2}\right)-2\left(1-e^{2}\right) K\left(e^{2}\right)}{e^{2} E(m)} .
$$

Then, the solution of (11) can be equivalent to obtain the zero match of function $G(e)$, while function $G(e)=$ 0 has unique solution in interval $e \in(0,1)$, the idea of dichotomy is used to solve (11) numerically. The value of $e, E\left(e^{2}\right)$, and $K\left(e^{2}\right)$ can be obtained simultaneously when solving (11). Initial values $x_{1}$ and $x_{2}$ as shown are taken in the solution because the range of ellipse eccentricity is $e \in(0,1)$. Thus, the more accurate value of contact ellipse parameter $\kappa$ is calculated if the error contact value is selected as small 
TABLE 1: Parameters of 7311B angular contact ball bearing.

\begin{tabular}{lc}
\hline Projects & Value \\
\hline Inner raceway diameter $/ \mathrm{mm}$ & 55 \\
Outer raceway diameter $/ \mathrm{mm}$ & 120 \\
Number of rolling elements & 12 \\
Ball nominal diameter/mm & 20.638 \\
Poisson's ratio of ball and raceways & 0.3 \\
Young's modulus of ball and raceways $/ \mathrm{N} \cdot \mathrm{m}^{-2}$ & $2.08 E 11$ \\
\hline
\end{tabular}

TABLE 2: Contact area size.

\begin{tabular}{lcccc}
\hline Projects & $\begin{array}{c}\text { Contact between } \\
\text { ball and inner } \\
\text { raceway }\end{array}$ & \multicolumn{2}{c}{$\begin{array}{c}\text { Contact between } \\
\text { ball and outer } \\
\text { raceway }\end{array}$} \\
& $a / \mathrm{mm}$ & $b / \mathrm{mm}$ & $a / \mathrm{mm}$ & $b / \mathrm{mm}$ \\
\hline Lundberg's algorithm $[27]$ & 3.6860 & 0.3220 & 2.9102 & 0.4670 \\
This method & 3.6893 & 0.3258 & 2.9059 & 0.4638 \\
Error \% & 0.0894 & 1.167 & 0.148 & 0.685 \\
\hline
\end{tabular}

TABLE 3: Maximum contact stress $\sigma_{\max }$ of contact area.

\begin{tabular}{lccc}
\hline Projects & $\begin{array}{c}\text { Lundberg } \\
{[27] / \mathrm{MPa}}\end{array}$ & $\begin{array}{c}\text { This } \\
\text { method/MPa }\end{array}$ & Error/\% \\
\hline $\begin{array}{l}\text { Inner raceway } \\
\begin{array}{l}\text { Ball while } \\
\text { contact with } \\
\text { inner raceway }\end{array}\end{array}$ & 2413.2 & 2382.8 & 1.26 \\
$\begin{array}{l}\text { Outer raceway } \\
\text { Ball while } \\
\text { contact with }\end{array}$ & 2108.2 & 2382.8 & 1.26 \\
outer raceway & 2108.2 & 2126.1 & 0.84 \\
\hline
\end{tabular}

as possible, and then contact parameters $a^{*}, b^{*}$, and $\delta^{*}$ are solved numerically.

The above numerical method is used to solve and analyze the stress field of 7311B angular contact ball bearing. Table 1 shows parameters of the bearing. The results are compared with results of Lundberg's simple algorithm [27] as shown in Tables 2 and 3.

From Table 2, some errors between contact area size got through numerical method and Lundberg's simple algorithm exist, but all less than $1.5 \%$. So the two methods can be verified with each other. The obtained maximum contact stresses are shown in Table 3. The maximum contact stress error at inner raceway is about $1.26 \%$ and about $0.84 \%$ at outer raceway. Thus, it can be seen that Lundberg's simple algorithm can roughly estimate the contact problem when calculation accuracy is not high.

3.2. Coupling Model of Fatigue Life and Damage for Rolling Bearing. Suppose contact fatigue damage of rolling bearings is isotropic; thus, the damage variable can be expressed as a scalar $D$ which means damage variable [30]:

$$
D=\frac{\delta_{S D}}{\delta s}
$$

where $\delta_{S D}$ is damaged area on the section and $\delta_{S}$ is a section area of infinitesimal.

Damage variable $D$ ranges from 0 to 1 . When $D$ is 0 , it means the section has not been injured. When $D$ is 1 , it indicates the section is full of damage and the bearing material is destroyed entirely. In fact, real material is destroyed before $D$ reaches 1 . Use $D_{c}$ to express the critical damage threshold of material, experiments show that $D_{c}$ has a value between 0.2 and 0.8 for metal material.

Based on damage mechanics, the rate of damage evolution of high-cycle fatigue links with damage variable $D$ and stress level $\sigma$, which expressed by a nonlinear equation as follows [30]:

$$
\frac{\mathrm{d} D}{\mathrm{~d} N}=f(\sigma, D)
$$

Based on the nonlinear equation, a two-parameter life model coupled with damage was proposed by Chaboche and Lesne [31] and Xiao et al. [32], which was widely used to predict the fatigue life of crack initiation:

$$
\frac{\mathrm{d} D}{\mathrm{~d} N}=\left[\frac{\Delta \sigma}{\sigma_{r}(1-D)}\right]^{m}
$$

where $\Delta \sigma$ is the maximum variation range of stress in a stress cycle, $\sigma_{r}$ and $m$ are two temperature-related material constants.

For rolling contact, note that the subsurface normal stresses on all the contact areas between raceway and rollers are compressive and prevent crack propagation, some assumptions are made [33]: (1) damage accumulation cannot be caused by subsurface pressure stress acting on cell nodes; (2) the shear stress acting on cell nodes help to damage accumulation and subsurface micro-crack propagation. This is consistent with the view of subsurface crack in rolling bearing only propagating in mode II (sliding mode crack). Thus, only shear stress amplitude $\Delta \tau$ can be used to predict the fatigue life. The damage evolution equation is expressed as follows:

$$
\frac{\mathrm{d} D}{\mathrm{~d} N}=\left[\frac{\Delta \tau}{\sigma_{r}(1-D)}\right]^{m}
$$

In view of the rolling contact fatigue damage is caused only by the shear behavior of material, the rolling contact fatigue is assumed to equivalent to torsional fatigue. So parameters $\sigma_{r}$ and $m$ can be obtained from torsional fatigue curve of a material:

$$
N_{f}=\frac{1}{(m+1)}\left[\frac{\sigma_{r}}{\Delta \tau}\right]^{m}=\left[\frac{2 \tau_{f}}{\Delta \tau}\right]^{B}
$$

where $\tau_{f}$ is the stress intensity factor and $B$ is the fatigue intensity index. In the torsional fatigue graph, $-1 / B$ is the slope of S-N curve and $\tau_{f}$ is the vertical axis intercept of S$\mathrm{N}$ curve. 


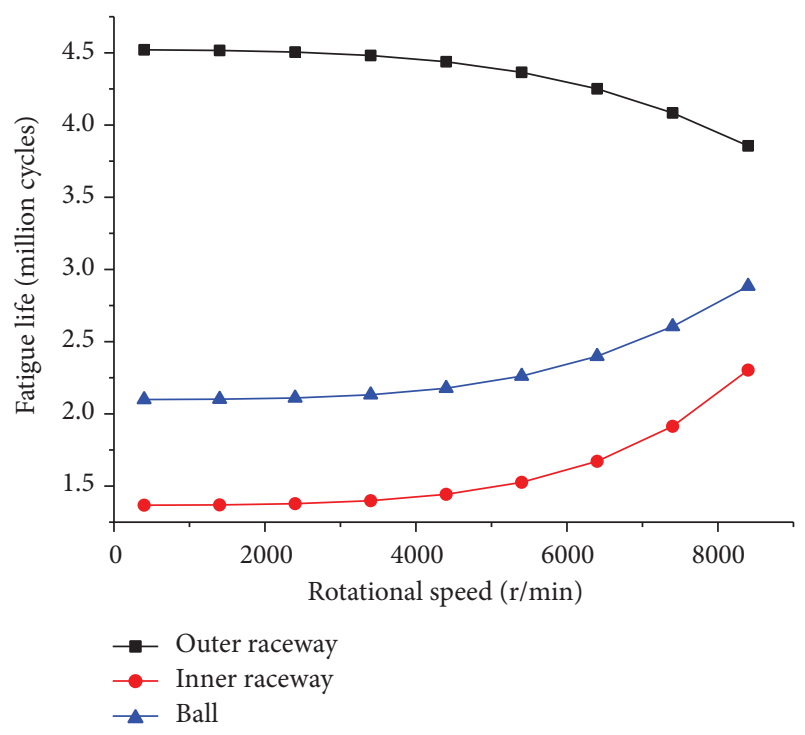

FIGURE 6: The change of fatigue life with rotational speed $n$.

From the equivalence of rolling contact fatigue failure mechanism and torsional fatigue failure mechanism, the stress parameters in both cases are assumed to be the same:

$$
\begin{aligned}
& m=B, \\
& \sigma_{r}=2 \tau_{f}(B+1)^{1 / B} .
\end{aligned}
$$

3.3. Simulation of Fatigue Life of Bearing Parts under Different Loads and Rotational Speeds. According to the above quasistatic model, contact angles and contact loads of a bearing change with different operation conditions, which have large effects on contact stress field and fatigue life of bearing parts. Ignore the impact of friction, lubrication and material inclusion on fatigue life of bearing parts, to same type rolling bearing, the fatigue life of bearing parts is mainly affected by rotational speed $n$, axial load $F_{a}$, and radial load $F_{r}$. This paper discusses the influences of these factors under the circumstance of fixed outer raceway and rotating inner raceway.

The contact angle and the contact load distribution of $7311 \mathrm{~B}$ angular contact ball bearing are calculated by the above modified Jones' model under different operating conditions. Substitute these calculated load data in life prediction model, and then the fatigue life of bearing parts is obtained.

3.3.1. Effect of Rotational Speed on Fatigue Life of Bearing Parts. While external load is invariable, contact angles and contact loads of a bearing will be significantly changed because of the increase of centrifugal force with rotational speed increasing. It will cause the life of bearing parts to be different. Setting axial load $F_{a}=50 \mathrm{kN}$ and radial load $F_{r}=0$, changing the spindle rotational speed, then the changes of fatigue life of bearing parts with rotational speed can be predicted as shown in Figure 6.

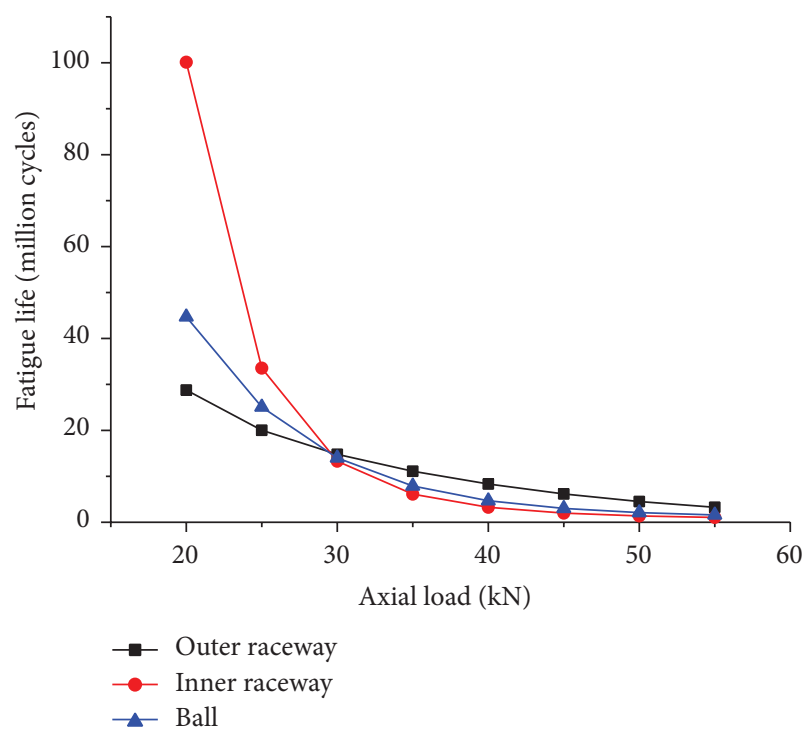

FIGURE 7: The change of fatigue life with axial load $F_{a}$.

As can be seen from Figure 6, the fatigue life of outer raceway is shortened gradually with the increasing of the rotational speed, and the fatigue life of inner raceway and ball tend to be larger. This is mainly due to the change of the maximum orthogonal shear stress at contact area caused by the variation of centrifugal force. The maximum orthogonal shear stress of the outer raceway will increase with the increase of centrifugal force but the orthogonal shear stress of inner raceway decreases. From the simulation results, the fatigue life of outer raceway is the longest ball is the second and inner raceway is the lowest.

3.3.2. Effect of Axial Load on Fatigue Life of Bearing Parts. In this case, only the axial load is changed while the rotational speed and the radial load are constant. This situation affects the stress field at contact area and further affects the fatigue life of a bearing. Figure 7 shows the variation trend of fatigue life of bearing parts with axial load $F_{a}$ under the case radial load $F_{r}=0$ and rotational speed $n=1400 \mathrm{r} / \mathrm{min}$.

As shown in Figure 7, increasing of axial load causes the decrease of fatigue life of ball, outer raceway and inner raceway. This is because the maximum orthogonal shear stress increases with the axial load increasing. However, due to the different increase rate of orthogonal shear stress, fatigue life of the three parts has different decline rates. The fatigue life of inner raceway falls at the fastest rate, ball second and outer raceway the slowest. We also see from the figure that when axial load less than $29 \mathrm{kN}$, the inner raceway has the longest life of the three parts. But when axial load bigger than $29 \mathrm{kN}$, the outer raceway life becomes the longest, though it does not appear to be much different among fatigue life of three parts.

3.3.3. Effect of Radial Load on Fatigue Life of Bearing Parts. The fatigue life of three bearing parts is also influenced by 


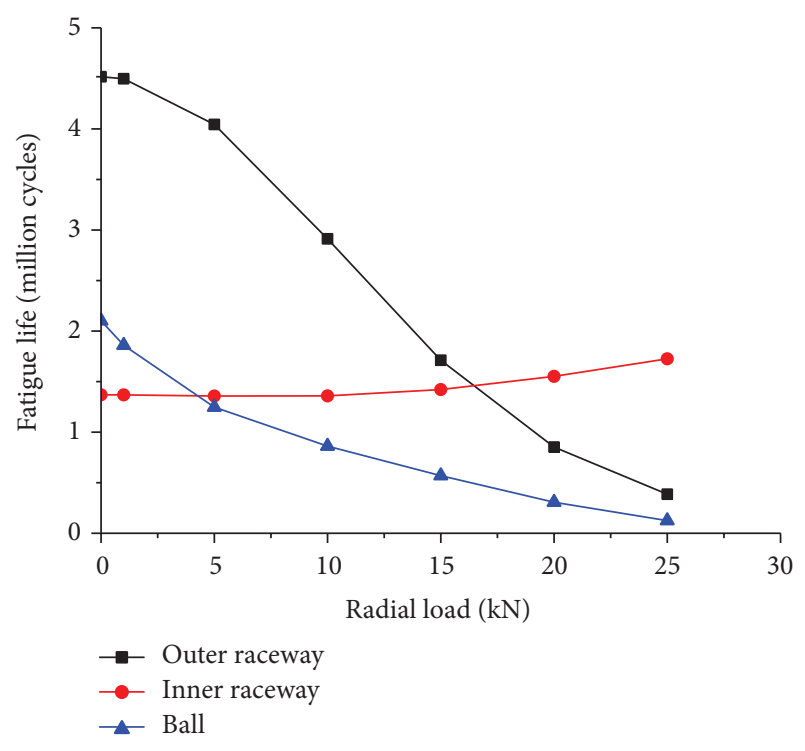

FIGURE 8: The change of fatigue life with radial load $F_{r}$.

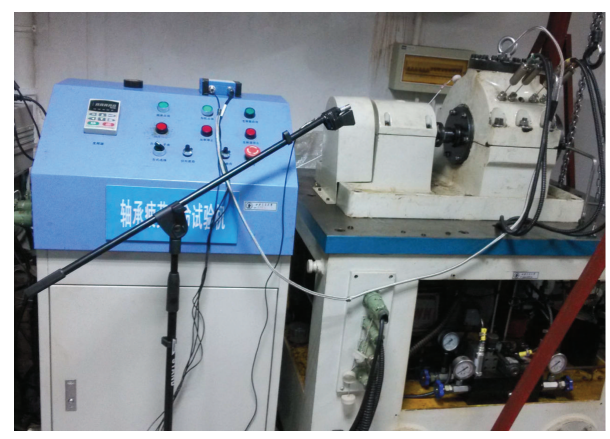

Figure 9: T20-60nF bearing fatigue life tester.

adjusting radial load and keeping axial load and rotational speed. The fatigue life trend changes with radial load $F_{r}$ under the case axial load $F_{a}=50 \mathrm{kN}$ and rotational speed $n=$ $1400 \mathrm{r} / \mathrm{min}$ is shown in Figure 8.

It can be found from Figure 8 that the fatigue life of outer raceway and ball decreases with the increasing radial load while the fatigue life of inner raceway increases slowly. At first the inner raceway life is the shortest among three parts. However, it exceeds ball life when radial load increases to about $5 \mathrm{kN}$ and exceeds outer raceway life when the load at $17 \mathrm{kN}$ or so. The increase of radial load leads to contact angle and contact load changing, which causes the maximum orthogonal shear stress of outer raceway and ball increase and inner raceway decrease. This situation results in the variation of bearing parts life.

3.4. Accelerated Life Test of Bearing. To verify the accuracy of the model, an accelerated life test was performed. The experimental work carried out on the T20-60nF bearing fatigue life tester as shown in Figure 9.7311B angular contact ball bearing was used in the test under one simulation working condition as $n=1400 \mathrm{r} / \mathrm{min}, F_{a}=50 \mathrm{kN}$ and
$F_{r}=0$. Four acceleration sensors and an acoustic emission sensor were installed to monitor the work status. Because the crack initiation life is difficult to determine in test, the life model cannot be quantitatively verified through comparing calculated life with test value. Because for bearing, the failure of one of the parts means the failure of whole bearing, if the first damage part of bearing in experiment is in agreement with simulated result, the model can be proved qualitatively. According to the simulation result, the fatigue life is $1.37 \times 10^{6}$ cycles, $4.52 \times 10^{6}$ cycles and $2.10 \times 10^{6}$ cycles for inner raceway, outer raceway and ball, respectively. It can be seen from the result that the life of the inner raceway is the lowest, that is, the inner raceway will be the most easily damaged part.

3.5. Results Analysis. There was no obvious damage that can be seen in outer raceway, inner raceway, and ball after experiment. Small dots were found on the surface of inner raceway as shown in Figure 10(a), while not found on outer raceway (shown in Figure 10(b)) and ball under VMS-1510G image measurement instrument. To further confirm the small dots on inner raceway were fatigue damage, the surface characterization of the three bearing parts was studied under scanning electron microscope (SEM), as shown in Figure 11.

Obvious pits about $25 \mu \mathrm{m}$ in size on the surface of inner raceway can be seen in Figure 11(a), which can be determined to microspalling caused by contact fatigue in morphology. On the other side, there was no pit on surface of outer raceway and ball as can be seen in Figures 11(b) and 11(c). This suggests that the fatigue damage first appears on inner raceway of bearing in accelerated life test. This result, which is consistent with the fatigue life model, demonstrates qualitatively the correctness of coupling model of life and damage.

\section{Conclusion}

In current study, a quasistatic model considering mechanical properties of whole bearing was introduced into the fatigue life calculation of angular contact ball bearing. Then, a coupling model of fatigue life and damage was established for rolling bearing. The fatigue life of bearing parts was analyzed under different rotational speed, axial load, and radial load. The results have shown that different working condition has a great influence on fatigue lives of bearing parts, under setting conditions in this paper, specifically as follows:

(1) With the increasing of rotational speed, the fatigue life of inner raceway and rollers is up while of outer raceway decline. The rotational speed does not much affect the order in which the damage appear on bearing parts.

(2) The fatigue life of three parts decreases with the axial load increasing, the fastest of which is the life of inner raceway. The rolling elements and raceways are damaged in different order under different load value. The inner raceway is easiest to emerge failure when axial load is higher than $29 \mathrm{kN}$.

(3) As radial load increasing, the fatigue life of outer raceway and rollers falls while of inner raceway rising 


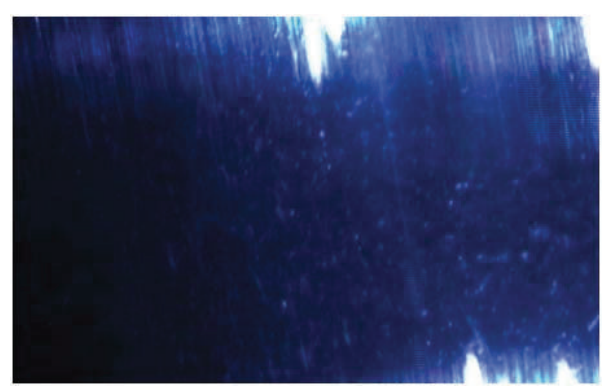

(a) Surface photo of inner raceway

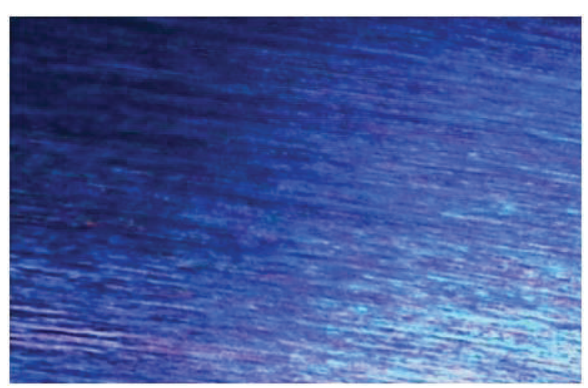

(b) Surface photo of outer raceway

FIGURE 10: Surface photo of raceways under VMS-1510G.

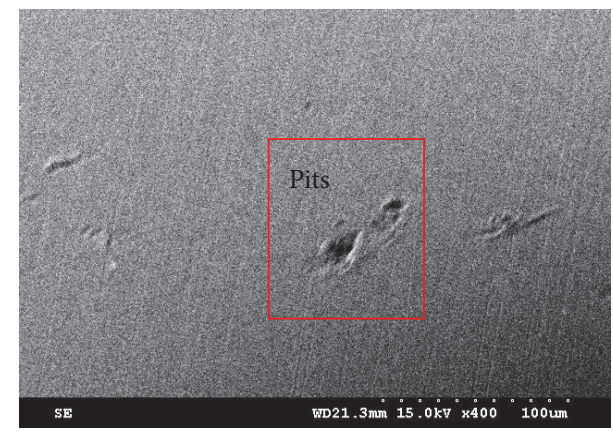

(a) Surface photo of inner raceway

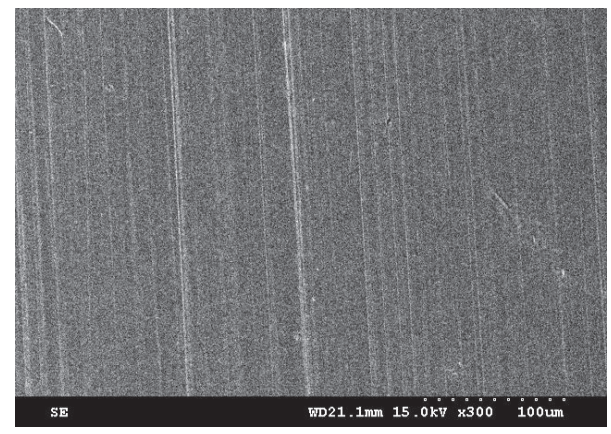

(b) Surface photo of outer raceway

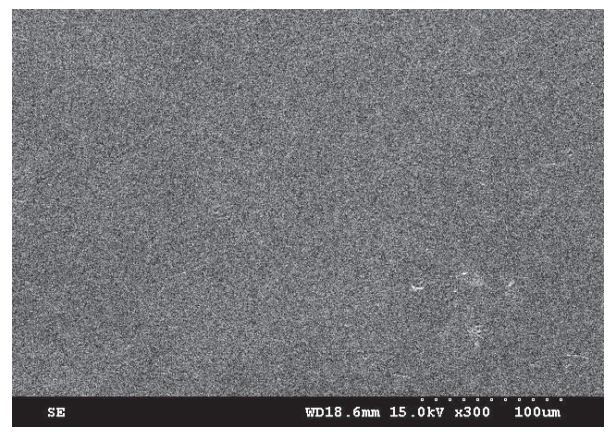

(c) Surface photo of ball

FIGURE 11: SEM photos of bearing parts.

a bit. The rollers are easiest to damage when load is larger than $5 \mathrm{kN}$.

\section{Conflict of Interests}

The authors declare that there is no conflict of interests regarding the publication of this paper.

\section{Acknowledgments}

This work is jointly supported by the National Natural Science Foundation of China (no. 51421004), the National Basic Research Program of China (no. 2011CB706606), and the Fundamental Research Funds for the Central University (CXTD2014001).

\section{References}

[1] R. B. Randall and J. Antoni, "Rolling element bearing diagnostics-a tutorial," Mechanical Systems and Signal Processing, vol. 25, no. 2, pp. 485-520, 2011.

[2] L. L. Jiang, Y. L. Liu, X. J. Li, and A. Chen, "Degradation assessment and fault diagnosis for roller bearing based on AR model and fuzzy cluster analysis," Shock and Vibration, vol. 18, no. 1-2, pp. 127-137, 2011.

[3] Y. Lei, J. Lin, Z. He, and Y. Zi, "Application of an improved kurtogram method for fault diagnosis of rolling element bearings," Mechanical Systems and Signal Processing, vol. 25, no. 5, pp. 1738-1749, 2011.

[4] P. Chang and B. Lin, "Vibration signal analysis of journal bearing supported rotor system by cyclostationarity," Shock and Vibration, vol. 2014, Article ID 952958, 16 pages, 2014. 
[5] M. S. Patil, J. Mathew, and P. K. RajendraKumar, "Bearing signature analysis as a medium for fault detection: a review," Journal of Tribology-Transactions of the ASME, vol. 130, no. 1, Article ID 014001, 7 pages, 2008.

[6] M. Cao and J. Xiao, "A comprehensive dynamic model of double-row spherical roller bearing-model development and case studies on surface defects, preloads, and radial clearance," Mechanical Systems and Signal Processing, vol. 22, no. 2, pp. 467489, 2008.

[7] N. Sawalhi and R. B. Randall, "Simulating gear and bearing interactions in the presence of faults. Part I. The combined gear bearing dynamic model and the simulation of localised bearing faults," Mechanical Systems and Signal Processing, vol. 22, no. 8, pp. 1924-1951, 2008.

[8] A. Rafsanjani, S. Abbasion, A. Farshidianfar, and H. Moeenfard, "Nonlinear dynamic modeling of surface defects in rolling element bearing systems," Journal of Sound and Vibration, vol. 319, no. 3-5, pp. 1150-1174, 2009.

[9] V. N. Patel, N. Tandon, and R. K. Pandey, "A dynamic model for vibration studies of deep groove ball bearings considering single and multiple defects in races," Journal of Tribology, vol. 132, no. 4, Article ID 041101, 10 pages, 2010.

[10] H.-R. Cao, Z.-J. He, and Y.-Y. Zi, "Modeling of a high-speed rolling bearing and its damage mechanism analysis," Journal of Vibration and Shock, vol. 31, no. 19, pp. 134-140, 2012 (Chinese).

[11] H. R. Cao, L. K. Niu, and Z. J. He, "Method for vibration response simulation and sensor placement optimization of a machine tool spindle system with a bearing defect," Sensors, vol. 12, no. 7, pp. 8732-8754, 2012.

[12] A. B. Jones, "A general theory for elastically constrained ball and radial roller bearings under arbitrary load and speed conditions," Journal of Fluids Engineering, vol. 82, no. 2, pp. 309320, 1960.

[13] T. A. Harris and M. N. Kotzalas, Essential Concepts of Bearing Technology, CRC Press, Boca Raton, Fla, USA, 5th edition, 2006.

[14] A. Grabulov, R. Petrov, and H. W. Zandbergen, "EBSD investigation of the crack initiation and TEM/FIB analyses of the microstructural changes around the cracks formed under Rolling Contact Fatigue (RCF)," International Journal of Fatigue, vol. 32, no. 3, pp. 576-583, 2010.

[15] F. Sadeghi, B. Jalalahmadi, T. S. Slack, N. Raje, and N. K. Arakere, "A review of rolling contact fatigue," ASME Journal of Tribology, vol. 131, no. 4, pp. 1-15, 2009.

[16] M. Taraf, E. H. Zahaf, O. Oussouaddi, and A. Zeghloul, "Numerical analysis for predicting the rolling contact fatigue crack initiation in a railway wheel steel," Tribology International, vol. 43, no. 3, pp. 585-593, 2010.

[17] A. S. Deshpande and J. M. Chandra Kishen, "Fatigue crack propagation in rocker and roller-rocker bearings of railway steel bridges," Engineering Fracture Mechanics, vol. 77, no. 9, pp. 14541466, 2010.

[18] Y. Liu and S. Mahadevan, "Probabilistic fatigue life prediction using an equivalent initial flaw size distribution," International Journal of Fatigue, vol. 31, no. 3, pp. 476-487, 2009.

[19] C. R. Liu and Y. Choi, "Rolling contact fatigue life model incorporating residual stress scatter," International Journal of Mechanical Sciences, vol. 50, no. 12, pp. 1572-1577, 2008.

[20] G. Lundberg and A. Palmgren, "Dynamic capacity of rolling bearings," Acta Polytechnica Mechanical Engineering Series, vol. 1, no. 3, p. 196, 1947.

[21] K. L. Johnson, Contact Mechanics, Cambridge University Press, Cambridge, UK, 9th edition, 1987.
[22] N. Raje and F. Sadeghi, "Statistical numerical modelling of sub-surface initiated spalling in bearing contacts," Proceedings of the Institution of Mechanical Engineers. Part J. Journal of Engineering Tribology, vol. 223, no. 6, pp. 849-858, 2009.

[23] B. Jalalahmadi, A new voronoi finite element fatigue damage model [Ph.D. thesis], Purdue University, West Lafayette, Ind, USA, 2010.

[24] N. Weinzapfel and F. Sadeghi, "Numerical modeling of subsurface initiated spalling in rolling contacts," Tribology International, vol. 59, pp. 210-221, 2013.

[25] A. Warhadpande, F. Sadeghi, M. N. Kotzalas, and G. Doll, "Effects of plasticity on subsurface initiated spalling in rolling contact fatigue," International Journal of Fatigue, vol. 36, no. 1, pp. 80-95, 2012.

[26] T. Holkup, H. Cao, P. Koláŕ, Y. Altintas, and J. Zelený, “Thermomechanical model of spindles," CIRP Annals-Manufacturing Technology, vol. 59, no. 1, pp. 365-368, 2010.

[27] T. A. Harris, Rolling Bearing Analysis, John Wiley \& Sons, New York, NY, USA, 1991.

[28] D. E. Brewe and B. J. Hamrock, "Simplified solution for elliptical-contact deformation between two elastic solids," Journal of Lubrication Technology, vol. 99, no. 4, pp. 485-487, 1977.

[29] I. N. Bronshtein, K. A. Semendiaev, and K. A. Hirsch, Handbook of Mathematics, Van Nostrand Reinhold, New York, NY, USA, 1985.

[30] J. Lemaitre, A Course on Damage Mechanics, Springer, Berlin, Germany, 1992.

[31] J. L. Chaboche and P. M. Lesne, "A non-linear continuous fatigue damage model," Fatigue and Fracture of Engineering Materials and Structures, vol. 11, no. 1, pp. 1-17, 1988.

[32] Y.-C. Xiao, S. Li, and Z. Gao, "A continuum damage mechanics model for high cycle fatigue," International Journal of Fatigue, vol. 20, no. 7, pp. 503-508, 1998.

[33] N. R. Nihar, Statistical Numerical Modeling of Subsurface Initiated Spalling in Bearing Contacts, Purdue University, 2008. 

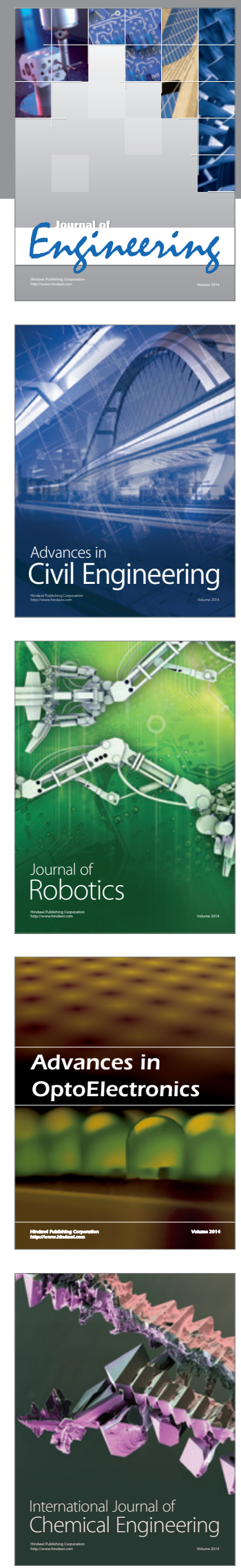

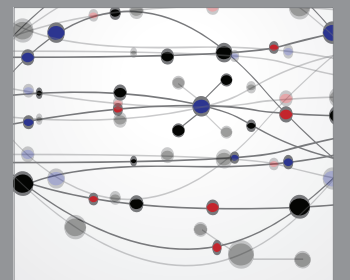

The Scientific World Journal
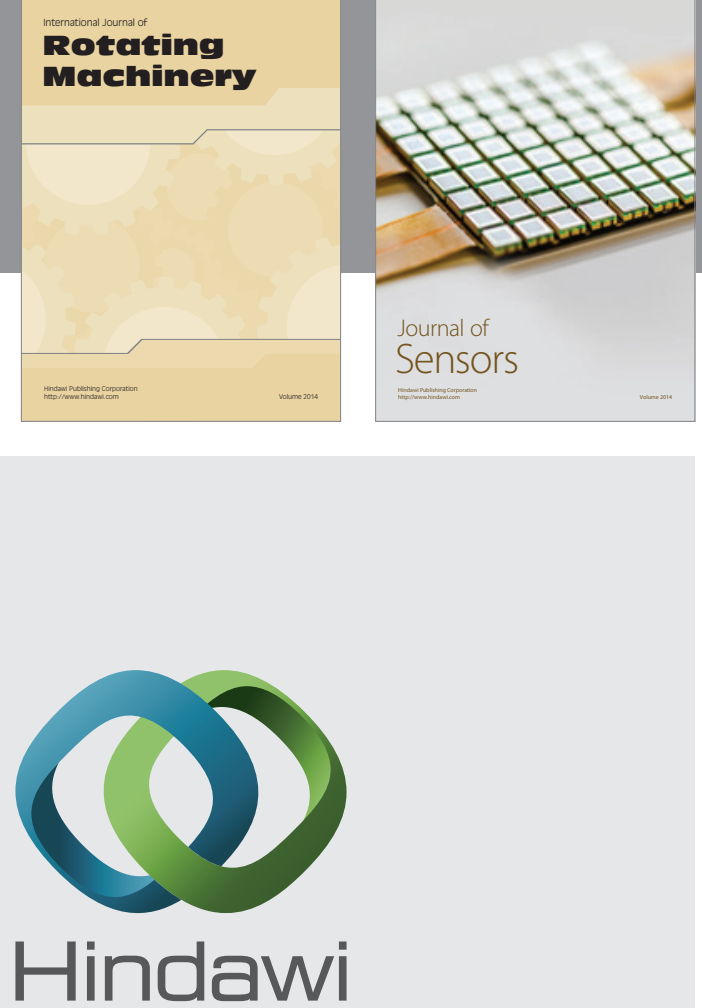

Submit your manuscripts at http://www.hindawi.com
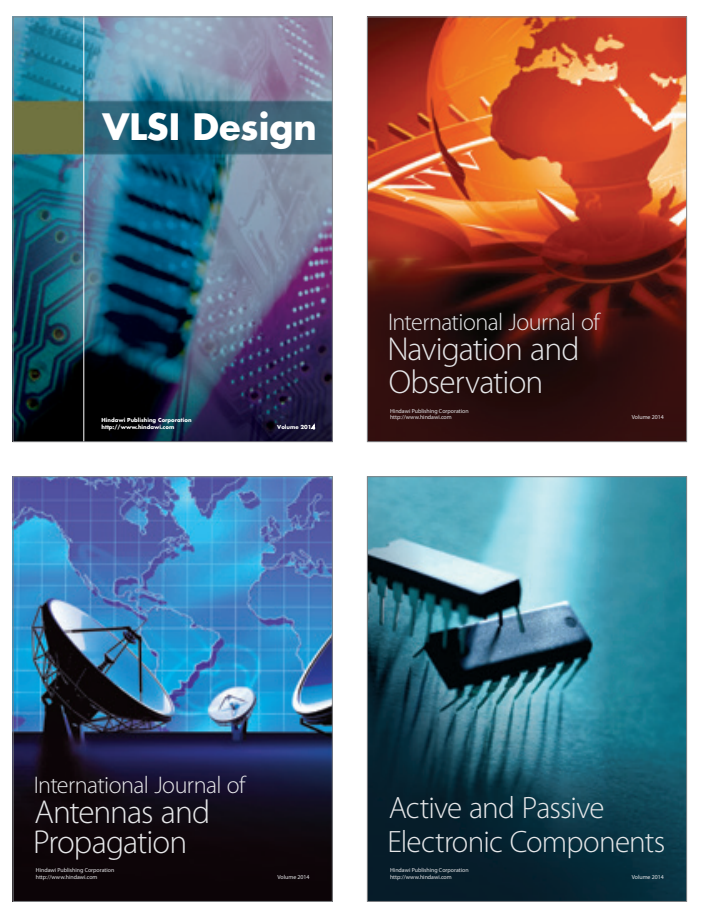
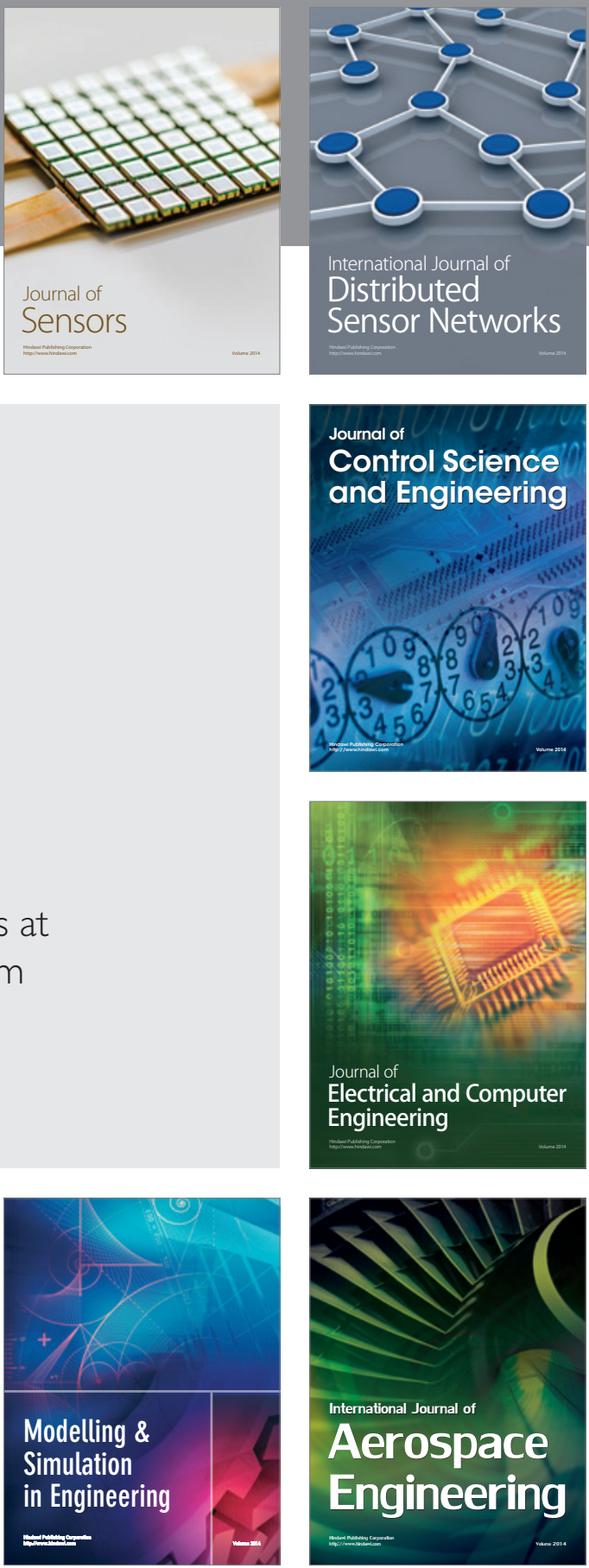

Journal of

Control Science

and Engineering
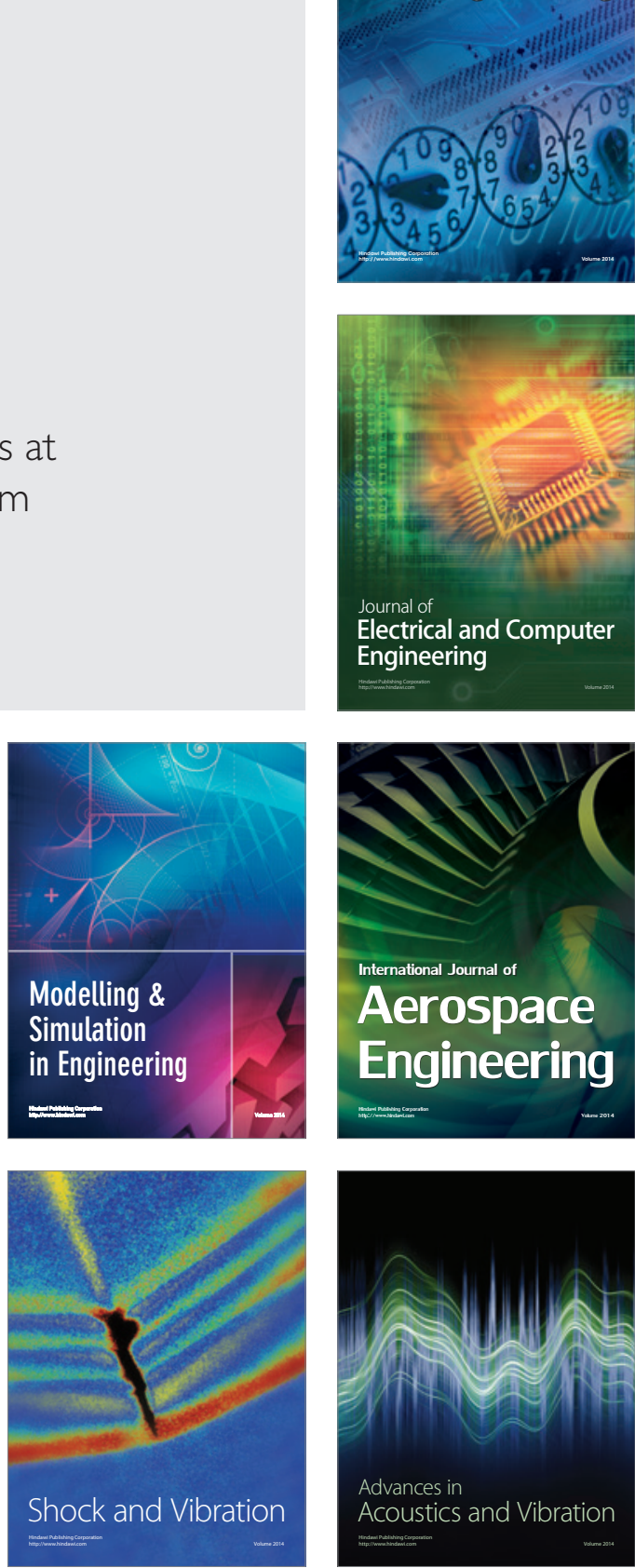